Part-time teachers still constitute the majority of the faculty overall, but academics with doctorates and with full dedication to the university are gaining ground. With their governance prerogatives, the new generation of academics control their universities, while cogovernance by students and administrative staff is in retreat.

Signs of the model's decline are numerous but not of the same nature across countries or across universities in a given nation. Brazil and Chile, for example, have moved on considerably; but the large national universities in Central America or Bolivia maintain their loyalty to the model, while Colombia, like Brazil, never did absorb much of its influence. And in Argentina and Mexico, for political and cultural reasons, it has been much easier for the newer or smaller universities to relinquish the model than has been the case for the highly visible Universidad Nacional Autónoma de México or the University of Buenos Aires.

The mores of the Latin American university are unlikely to vanish without a trace, given the persistent connection of the largest public universities in the region to some elements of the Latin American model-such as participatory governance, free tuition, and institutionalized political engagement. Further, the traditions of political awareness, social critique, and outreach to the underprivileged seem especially relevant today, both in Latin America and globally. As with other phenomena of cultural diffusion, the concept of the research university is likely to evolve in Latin America into a form that recognizes and integrates in some manner the tradition of the Latin American university

Author's note: This article is a shorter version of "Is there a Latin American Model of the University?" published in Comparative Education Review 52(I), Feb. 2008.

\section{Measuring Institutional Quality in Argentina: The Devil Is in the Details}

\section{LIZ REISBERG}

Liz Reisberg is research associate at the Center for International Higher Education, Boston College. E-mail: reisberg@bc.edu.

$\mathrm{M}$ ore than a decade after launching a national quality assurance program, Argentina may be pursuing a worthy cause on the wrong path. The country has adopted schemes in use elsewhere without accommodating conditions that make higher education in Argentina very different. Measuring itself by the evaluation criteria applied elsewhere, Argentine univer- sities are diverting attention and resources from improving their primary activity_teaching.

\section{Context and Challenges}

Higher education in Argentina has undergone many of the rapid changes experienced in other developing countries. Demand for access to university education has grown precipitously during recent decades, and the government has allowed a private sector to expand while also creating new public universities. There are currently 8I (43 private, 38 public) universities serving an enrollment in 2007 of slightly more than $\mathrm{I} .5$ million. Twenty-five years earlier enrollment was under 400,000.

In Argentina this expansion took place under very precarious economic conditions. The I980s ended with staggering hyperinflation that did not abate until i991. The economy prospered briefly, then suffered several setbacks during the I990s, culminating in a 75 percent devaluation of the peso in $200 I$.

At precisely the time when enrollment was exploding, public universities were struggling with shrinking or devalued budgets, and a nascent tuition-dependent private sector was forced to operate within severe limitations. Consequently, universities in both the public and private sector have tended to be seriously underfinanced. In the midst of these significant economic challenges and constraints, higher education suddenly confronted new demands for accountability and quality assurance.

\section{Mimicking Others}

During the early I990s, fueled by assessments and funding from the World Bank, the Ministry of Education initiated a national dialogue about quality in higher education. International experts were invited to present schemes in use elsewhere in the world. Argentine educators attended conferences abroad to learn more about international trends and programs. A new law of higher education, passed in I995, presented universities with the obligation of participating in an array of evaluations.

In practice, the new program resembled quality assurance schemes employed elsewhere-self study followed by external evaluation, all reviewed by the CONEAU (Consejo Nacional de Evaluación y Acreditación Universitaria), the new parastatal coordinating commission. So far, so good. The problem was (and is) what to measure. In other words, by which criteria are Argentine universities to be evaluated?

Quality is a concept not unlike "success"-although everyone wants it, few can define it in a way that will suit diverse audiences. Not defining quality based on the unique characteristics of Argentine higher education may be a serious flaw. Lacking experience and a process for creating indigenous criteria, Argentina adopted measures, as well as methods, used by other cultures and societies. Thus, universities are measuring institutional characteristics such as the number of profes- 
sors with graduate degrees, publications, research productivity, retention rates, and management effectiveness. But Argentina is not France, nor Spain, nor the United States, nor Chile. How useful are these measures, used for evaluating the quality of higher education in those countries, to Argentina? It is important to consider several key characteristics in which higher education in Argentina differs from higher education elsewhere.

Tradition and economics have conspired to make interna-

Quality is a concept not unlike "success"-
although everyone wants it, few can define it in a
way that will suit diverse audiences.

tional criteria used to measure quality impractical and, in the short term, meaningless. This critique is not meant to imply that such criteria would not be useful in the long term; the only point is that this is not where evaluation should start in Argentina. The risk of using international standards now is that limited resources will be redirected, and more timely (and more relevant) priorities might be pushed aside. For example, very few graduate programs were offered by universities in Argentina until the mid-I980s. Given that traditionally a graduate degree has not been a prerequisite for university-level teaching, not surprisingly only a small percentage of professors currently hold one. Budget challenges have caused most universities to opt for a largely part-time faculty. According to annual statistics published by the Ministry of Culture and Education, barely I2 percent of the faculty at public universities are hired in full-time positions.

Argentina's universities have little, if any, tradition of research, which has been conducted at independent institutes in the past. Moreover, predominantly part-time faculty and a limited budget to invest in infrastructure restricts the universities' future research capacity. On average, the number of students graduating from public universities is less than 24 percent of the number entering and only slightly higher $(26 \%)$ in the private sector. Argentina has not held a tradition of providing student services (i.e., academic advising, career counseling, personal counseling, or financial aid).

Senior administrators are elected by the faculty, students, and staff. Newly elected officials appoint their own management team, inhibiting the development of a local cadre of administrators with professional management experience.

\section{Measure What You Do}

Given current conditions, budgets, and tradition, the criteria used to evaluate university quality elsewhere make little sense for Argentina. What universities do in Argentina (almost exclusively) is teach. So, to measure the quality of Argentine universities should the primary focus of evaluation not be teaching? Yet in the processing of mimicking other countries, this activity has been nearly overlooked. Some institutions have introduced student evaluations of faculty, but this process is in its infancy and requires more effective instruments as well as skills to analyze and make use of data collected. And this is only one small part of an effort to improve teaching.

Should scant resources not be focused on developing excellent teaching rather than attempting to develop resource capacity in an environment that cannot sustain it? Would universities not see more immediate benefit by offering faculty opportunities to integrate new technology and new pedagogy in the classroom?

The cascade of evaluations has mainly demonstrated how little most universities knew about themselves. The process of self-study launched a scramble for data about students, professors, and facilities and the implementation of new systems to track data in the future. Improving quality is most effective when it begins with an accurate and honest assessment of current conditions and realities. Universities are creating baselines against which future improvements can be measured. Key now is how these data are used and what the focus of institutional development will be-an isomorphic exercise or a carefully considered process that addresses the needs and realities of higher education in Argentina.

\section{Education Reform in Montenegro: Public and Private Tensions}

\section{Joseph Stetar and Vucina Zoric}

Joseph Stetar is a professor of higher education at Seton Hall University. Address: Seton Hall University, Jubilee Hall, South Orange, NJ 07079, USA. E-mail: stetarjo@shu.edu. Vucina Zoric is assistant professor at the University of Montenegro and in spring 2007 was a visiting scholar at Seton Hall University. E-mail: vucina@cg.ac.yu.

$\mathrm{M}$ ontenegro, one of the six republics of the former Yugoslavia and one of the newest members of the United Nations (2006), is witnessing a transformation and restructuring of higher education. A small state with a population of approximately 650,000, Montenegro is unable to support complex and multiple systems of higher education. Currently there is one state institution, the University of Montenegro, which was established in 1974 and enrolls I4,000 students across ig faculties. There are also two private institutions: the University of the Mediterranean, established in 2005 and enrolling I,००० students in six faculties; and Univerzitates, 